\title{
Computer-Based Auditory Training Programs for Children with Hearing Impairment - A Scoping Review
}

\author{
Manohar Nanjundaswamy ${ }^{1}$ Prashanth Prabhu ${ }^{2}$ Revathi Kittur Rajanna ${ }^{2}$ \\ Raghavendra Gulaganji Ningegowda ${ }^{1}$ Madhuri Sharma ${ }^{1}$
} ${ }^{1}$ Department of Electronics, All India Institute of Speech and Hearing
Ringgold Standard Institution, Mysore, Karnataka, India
${ }^{2}$ Department of Audiology, All India Institute of Speech and Hearing
Ringgold Standard Institution, Mysore, Karnataka, India
Address for correspondence Prashanth Prabhu, MSc, Department of Audiology, All India Institute of Speech and Hearing, Naimisham Campus Manasagangothri, Mysore, Karnataka 570006, India (e-mail: prashanth.audio@gmail.com).

Int Arch Otorhinolaryngol 2018;22:88-93.

\begin{abstract}
Introduction Communication breakdown, a consequence of hearing impairment $(\mathrm{HI})$, is being fought by fitting amplification devices and providing auditory training since the inception of audiology. The advances in both audiology and rehabilitation programs have led to the advent of computer-based auditory training programs (CBATPs).

Objective To review the existing literature documenting the evidence-based CBATPs for children with HIs. Since there was only one such article, we also chose to review the commercially available CBATPs for children with HI. The strengths and weaknesses of the existing literature were reviewed in order to improve further researches.

Data Synthesis Google Scholar and PubMed databases were searched using various combinations of keywords. The participant, intervention, control, outcome and study design (PICOS) criteria were used for the inclusion of articles. Out of 124 article abstracts reviewed, 5 studies were shortlisted for detailed reading. One among them

Keywords

- auditory training

- computer-based

- auditory rehabilitation

- software satisfied all the criteria, and was taken for review. The commercially available programs were chosen based on an extensive search in Google. The reviewed article was wellstructured, with appropriate outcomes. The commercially available programs cover many aspects of the auditory training through a wide range of stimuli and activities. Conclusions There is a dire need for extensive research to be performed in the field of CBATPs to establish their efficacy, also to establish them as evidence-based practices.
\end{abstract}

\section{Introduction}

It is well known that hearing impairment (HI) causes breakdowns in communication. The existence of hearing loss has increased over time and reached alarming levels. According to a report by the World Health Organization (WHO), ${ }^{1}$ there are 360 million (5.3\% of the world's population) people in the world with disabling hearing loss, out of which 32 million (9\%) are children. The report also suggests that the prevalence of disabling hearing loss in children is greatest

received

January 3, 2017

accepted

February 16, 2017

published online

April 28, 2017

10.1055/s-0037-1602797. ISSN $1809-9777$. in Southern Asia, Asia Pacific and Sub-Saharan Africa. These figures only direct us toward the early identification, diagnosis and further development of a more efficient rehabilitation program to allow effective communication for all. The rehabilitation of children with $\mathrm{HI}$ is considered of utmost importance to enable them to be on par with their peers in terms of communication. Following the diagnosis and the fitting of the appropriate hearing device, the child must undergo auditory therapy alongside speech therapy. ${ }^{2-9}$

Copyright $\odot 2018$ by Thieme Revinter

Publicações Ltda, Rio de Janeiro, Brazil

License terms 
Rehabilitation after the fitting of an amplification device has evolved over the years from lip reading to methods such as the auditory verbal therapy. Typically, there are three ways of providing auditory training: individually, in groups, and at home with computer-based training. Individual therapy is often inaccessible and demands a lot of resources, like an appropriate set up, clinical personnel and time, and these services are non-reimbursable. ${ }^{2,9,10}$ This is a concern especially in a country like India, where there is less awareness and the rural population is mostly inaccessible. On the other hand, group therapy can be efficient in terms of time and cost. ${ }^{11}$ However, the lack of individual attention becomes a major concern.

With the advancement of technology, computer-based programs have attracted considerable attention amongst researchers wishing to develop new programs that target the development of listening skills. ${ }^{12-14}$ Several computerbased rehabilitation programs for $\mathrm{HI}$ have been designed and put forward in the market. However, only a handful of them have documented efficacy measures. Those that are documented are mostly computer-based auditory training programs (CBATPs) for adults. Although there are several CBATPs for children with $\mathrm{HI}$ in the market, their efficacy is not well documented. The literature reports some objective evidence in support of CBATPs for adults. ${ }^{3,7,15}$ However, Pallarito $^{9}$ has pointed out that such research is limited, and the profession lacks clinical guidelines for the use of CBATPs.

Sweetow and Palmer ${ }^{16}$ reported a systematic review of the evidence for the efficacy of individual auditory training in adults. Only six articles out of 42 met the criteria of their review. The review highlighted that although there are several publications on auditory training, very few met the rigorous scientific criteria, such as lack of control groups, small numbers of subjects etc., set to qualify the results as evidence. They suggested that determining the effectiveness is crucial, and that further studies must focus of adapting well-defined criteria to be proved as evidence-based approach. Bourns et al $^{17}$ also reviewed studies on auditory training in older adults (50 years or above) with mild to moderate sensorineural hearing loss. However, they reported methodological weaknesses similar to those reported in Sweetow and Palmer, ${ }^{16}$ and lack of statistically significant clinically relevant outcomes. They suggested that flaws in the current evidence base should be used to stimulate the future directions of auditory training (AT) investigation rather than only change the existing techniques. Other reviews of individual CBATPs for adults with $\mathrm{HI}^{18,19}$ also identified similar research gaps that hinder the reviewers from establishing CBATPs as a well-defined evidence-based practice for adults.

In today's world, the use of technology and electronic gadgets is not limited only to adults. Children are adept at using gadgets, especially for gaming and learning. The existence of several apps to teach phonetics, vocabulary, school-based academic curriculum etc. is a sure indicator of their interest in using interactive computer programs for learning, in all age groups. With this advancement and the documented evidence of the benefits of using CBATPs with adults, several CBATPs for children were launched in the market as well. However, there is little or no evidence to document the efficacy of these programs. A careful assessment of the existing programs and their structure is the first step towards strengthening the evidence of the benefits of CBATPs for children. This will also help identify the gaps and areas that need improvement and subsequently instigate more research that will aim at developing and establishing evidence-based practices ${ }^{17}$ in CBATPs for children. The results obtained with randomized controlled trials will help advance the scientific understanding of whether CBATPs can be of help to patients with HI. However, such scientific knowledge typically evolves from a more primitive level of expert opinions, case reports, case series, or the clinical experience.

The aim of the present article was to carefully examine the current CBATPs designed for children with $\mathrm{HI}$ and the documentation of their efficacy, if any. This comprehensive review will update the researchers and clinicians about the programs they can successfully use for children with HI. It will also enable the proprietors of the existing programs to document appropriate efficacy measures and help the upcoming researches to adequately fill the voids by developing well-designed programs with suitable efficacy measures.

\section{Review of the Literature}

The method for reviewing in this study involved searching databases using different combinations of keywords. The databases searched were PubMed and Google Scholar. In addition, several back references of articles were considered. In total, the abstracts of 124 articles were reviewed. Out of these, 120 were rejected. The participant, intervention, control, outcome and study design (PICOS; Moher et $\mathrm{al}^{20}$ ) criteria were used for the inclusion/exclusion of the articles. The following are the criteria chosen.

- Participant: children ( $<18$ years) with or without hearing aid/cochlear implant/any other listening device, with HI of any degree. Individual or group electronic device.

- Control: comparison with a group undergoing regular therapy.

- Outcome: 1+ outcome measure related to language, speech intelligibility, and/or communication (behavioral or self-reported).

- Study design: randomized controlled, non-randomized controlled, cohort, repeated measure (with/without control).

The keywords used for the search were: hearing loss or hard of hearing or hearing impairment or hearing aid or cochlear implant or computer-based or app-based or children AND auditory therapy or auditory learning. Following this initial search, five articles were thoroughly reviewed. Four articles out of the five failed to meet the criteria due to the use of just one or no outcome measures. One article was shortlisted to be discussed here. (-Table 1). 
Table 1 Descriptive summary of the article that met all inclusion criteria

\begin{tabular}{|c|c|c|c|c|c|}
\hline Reference & Design & Intervention & Outcomes & Results & Comments \\
\hline Glyde et $\mathrm{al}^{21}$ & $\begin{array}{l}\text { Repeated } \\
\text { measure }\end{array}$ & $\begin{array}{l}\text { LiSN \& Learn Auditory Training Software, }{ }^{22} \\
\text { SSQ, }{ }^{24} \text { LIFE }^{25}-20 \text { minutes per day, } 5 \text { days a } \\
\text { week until } 60 \text { sessions were completed }\end{array}$ & $\begin{array}{l}\text { LiSN-S Test, }{ }^{22} \text { SSQ, } \\
\text { LIFE, }^{25} \text { BKB sentences }\end{array}$ & $\begin{array}{l}\text { No significant improvement in } \\
\text { both groups in spatial processing. } \\
\text { No significant effect of age }\end{array}$ & $\begin{array}{l}\text { Small N, not } \\
\text { blinded }\end{array}$ \\
\hline
\end{tabular}

Abbreviations: BKB, Bamford-Kowal-Bench; LIFE, Listening Inventory for Education: Student Appraisal of Listening Difficulty; LiSN-S, Listening in Spatialized Noise - Sentences; N. number; SSQ, Speech, Spatial and Qualities of Hearing Scale.

Since the literature lacks well-defined studies on children using CBATPs, the authors decided to review the commercially available auditory training programs specially designed for children with HI. Although studies reporting their efficacy do not exist, a review of the programs might provide useful information for the clinicians and instigate the researchers to establish these programs as evidence-based practices. The following programs were chosen to be reviewed.

- Angel Sound Training (TigerSpeech Technology, Hefei, China)

- Otto's World of Sounds (Oticon, Somerset, NJ, US)

- Programs offered by Advanced Bionics (Valencia, CA, US)

- Programs offered by MED-EL (Innsbruck, Austria)

- Programs offered by Cochlear (Sydney, Australia)

The article by Glyde et $\mathrm{al}^{21}$ is a comprehensive and carefully designed study to see the effect of the LiSN \& Learn training software in hearing impaired children and adults. This article is in continuation with two other studies evaluating the efficacy of the LiSN \& Learn training software in normal hearing children diagnosed with spatial processing disorder. ${ }^{22,23}$ This study also aimed at establishing the efficacy of the software in the population with HI keeping in mind the hypothesis that the spatial processing in people with normal hearing and in those that are hearing impaired is different. Since the spatial processing deficits in the hearing impaired population arise from peripheral changes (interaural time and level differences are usually distorted before they leave the cochlea), rather than from higher order deficits, ${ }^{22}$ the study hypothesized that training would not bring about a significant difference in their spatial processing. This hypothesis was proved right with the help of parametric statistics. The study also noticed no significant difference between the two groups. The reason for this is stated in an unclear manner.

The study uses more than one outcome measure:

- Listening in Spatialized Noise - Sentences (LiSN-S) test; ${ }^{22}$

- Speech, Spatial and Qualities of Hearing Scale (SSQ); ${ }^{24}$

- Listening Inventory for Education: Student Appraisal of Listening Difficulty (LIFE); ${ }^{25}$ and

- Bamford-Kowal-Bench (BKB) sentences. ${ }^{26}$

The two objective outcome measures were used for perception of sentences in both quiet and noise and at different azimuths. This is a well-chosen measure, as the training software focuses on the ability to separate the signal from the background noise. An outcome measure on the same lines will provide an appropriate measure of the observed improvement. Additionally, the two questionnaires chosen give a subjective angle on the perception of speech in noise. The literature also suggests the use of electrophysiological tests, like auditory brainstem measures that assess the perception of speech in noise and track therapeutic improvement. ${ }^{27}$ The inclusion of these electrophysiological tests to correlate with other measures could have helped confirm their hypothesis about the comparison of spatial processing in normal hearing individuals and in those with $\mathrm{HI}$. Also, the small sample size restricts one from generalizing the effects with confidence. However, the study as a whole is well-structured and reported.

In order to review the CBATPs that are commercially available, the authors followed a structure used by Zhang, Miller and Campbell. ${ }^{28}$ Twenty-nine features of the programs to be discussed were grouped under three categories: general product and purchase information; design features of the training paradigm; and auditory and communication targets. The programs were then discussed in accordance with these features.

\section{General Product and Purchase Information}

\section{Angel Sound Training}

Angel Sound Training is a product developed by TigerSpeech Technology and distributed by the Emily Shannon Fu Foundation. It is a PC-based interactive auditory training and hearing assessment program that is a potentially selfadministrable auditory rehabilitation program. It has 9 modules that cover a wide range of stimuli and activities, ranging from non-verbal stimuli to syllables, words, and sentences in both quiet and in noise. It also has music and cognition-based activities. Each module has different levels of difficulty. It is the most comprehensible program reviewed by the authors of the present study, and it is encompassing in terms of the concepts covered. It is available for download on the internet freely.

\section{Otto's World of Sounds}

Otto's World of Sounds is a multimedia auditory training tool from Oticon. It was based on the French training software called "La Souris Bleue" (The Blue Mouse), developed in 1999 by French audiologist Alain Vinet and computer scientist Denis Barbier. It is available free of cost along with hearing aids purchased from Oticon for children below 8 years of age.

Otto's world is designed to help hearing impaired children in the age range of 2.5 to 8 years to improve their auditory 
skills by detecting, discriminating, and identifying sounds. This program runs through a CD-ROM. It has interactive activities that also require the caretaker's participation in terms of assisting the child. It provides the child with 10 different auditory environments, each focusing on 10 different sounds, and includes activities for sound detection, discrimination, and identification, using sounds from the child's everyday environment. Within each of these environments, there are activities for discovery, memory, and recognition, which follow a hierarchy. The concept of building vocabulary is also addressed.

\section{Programs Offered by Advanced Bionics}

Advanced Bionics is a cochlear implant company that has many rehabilitation-based programs for children and adults. The programs for children are: $\mathrm{AB}$ Listening Adventures and VocAB Scenes. AB Listening Adventures is best suited to children aged between 4 and 10 years. The program is designed to guide the development of listening and language skills using six different story-based games that focus on listening for multiple elements, plurals, pronouns or minimal pairs. It focuses on listening for words in sentences. VocAB Scenes is also best suited to children aged between 4 and 10 years. It is a scene-based vocabulary-building app, which utilizes everyday scenes from the child's environment to introduce new vocabulary. It has three different games for each scene.

\section{Programs Offered by MED-EL}

MED-EL is another cochlear implant company that has rehabilitation programs for children and adults. One of them is called SoundScape. This program have free download from the company's website. It has eight modules, and only the first six are for children. The modules for children follow a hierarchy for different age groups: Starting out - 0-2 years; Ms. MacDonald's Shed - 2+ years; Old MacDonald's Farm - 2+ years; Let's go Shopping - $6+$ years; Telling Tales $-10+$ years; Continents and Oceans - teens. These modules cover age appropriate stimuli ranging from words and phrases to sentences and paragraphs using different activities that have varying levels of difficulty. The modules also have sublevels.

\section{Programs Offered by Cochlear}

Cochlear is also a cochlear implant company that provides users with rehabilitation programs for all ages. The programs for children are: HOPE words and Kaci's games. HOPE words is a preliminary app that focuses on phonetics and basic vocabulary building through alphabet-based activities. Kaci's games is about remembering matching objects. The cards show pictures of animals that have corresponding sounds.

\section{Design Features of the Training Paradigm}

A summary of the design features of the training programs taken for review is provided in - Table 2 .

\section{Auditory and Communication Targets}

A summary of the goals with which the programs were designed in each of these CBATPs is shown in - Table 3.

\section{Discussion}

The primary goal of this review article was to examine the existence of evidence-based effective CBATPs for children. The secondary goal was to update and expand the knowledge on the available CBATPs for children. The review resulted in only one article that satisfied all the criteria considered. This, in turn, instigated the authors to include the review of the commercially available CBATPs designed for children with $\mathrm{HI}$. The strength of this review is that it gives the present-day clinicians and researchers up-to-date information about the programs available.

This article emphasizes the fact that there is extremely little documented evidence on the efficacy of the CBATPs used for children with HI. It is evident that there are plenty of commercially available CBATPs that address most concepts related to auditory training. They also have activities catering to different age groups. However, there is no evidence to establish their efficacy. There is clear evidence about the rise in the use of electronic gadgets among the general population in today's world. App/software-based learning programs have become very popular and are highly sought after. Additionally, keeping in mind other factors like the issue of the access to clinics, cost effectiveness etc., CBATPs are gaining immense popularity.

On the other hand, the importance of early identification and intervention is a well-established fact. ${ }^{29}$ The concept of critical age also encourages most of the learning to happen as early as possible. It is important that the child receives the most auditory stimulation in his/her early years in order for the age appropriate auditory development to take place.

Table 2 Summary of the design features of the CBATPs

\begin{tabular}{|l|l|l|l|l|l|}
\hline & $\begin{array}{l}\text { Angel } \\
\text { Sound } \\
\text { Training }\end{array}$ & $\begin{array}{l}\text { Otto's } \\
\text { World of } \\
\text { Sounds }\end{array}$ & $\begin{array}{l}\text { Programs } \\
\text { offered by } \\
\text { AdvBio }\end{array}$ & $\begin{array}{l}\text { Programs } \\
\text { offered by } \\
\text { MED-EL }\end{array}$ & $\begin{array}{l}\text { Programs } \\
\text { offered by } \\
\text { Cochlear }\end{array}$ \\
\hline Progress measurements & $\checkmark$ & - & - & - & - \\
\hline $\begin{array}{l}\text { Adaptive to client progress; level of difficulty automatically } \\
\text { adjusted }\end{array}$ & $\checkmark$ & - & - & - & $\checkmark$ \\
\hline Manufacturers provide a recommended time commitment & - & - & - & - & - \\
\hline Therapist involvement required & - & $\checkmark$ & $\checkmark$ & $\checkmark$ & - \\
\hline
\end{tabular}

Abbreviation: AdvBio, Advanced Bionics; CBATPs, computer- based auditory training programs. 
Table 3 Summary of auditory and communication targets in the CBATPs

\begin{tabular}{|c|c|c|c|c|c|}
\hline & $\begin{array}{l}\text { Angel } \\
\text { Sound } \\
\text { Training }\end{array}$ & $\begin{array}{l}\text { Otto's } \\
\text { World of } \\
\text { Sounds }\end{array}$ & $\begin{array}{l}\text { Programs } \\
\text { offered by } \\
\text { AdvBio }\end{array}$ & $\begin{array}{l}\text { Programs } \\
\text { offered by } \\
\text { MED-EL }\end{array}$ & $\begin{array}{l}\text { Programs } \\
\text { offered by } \\
\text { Cochlear }\end{array}$ \\
\hline Intended to assist hearing aid users & $\boldsymbol{\nu}$ & $\boldsymbol{\nu}$ & - & - & - \\
\hline Intended to assist $\mathrm{Cl}$ users & レ & - & $\boldsymbol{\nu}$ & $\boldsymbol{\nu}$ & $\boldsymbol{\nu}$ \\
\hline From a variety of speakers & $\boldsymbol{\nu}$ & - & - & $\boldsymbol{\nu}$ & - \\
\hline In background noise/ multi-talker & レ & - & - & レ & - \\
\hline Of connected speech & $\boldsymbol{\nu}$ & $\boldsymbol{\nu}$ & $\boldsymbol{\nu}$ & $\boldsymbol{\nu}$ & $\boldsymbol{\nu}$ \\
\hline Of vowels & レ & レ & $\boldsymbol{V}$ & レ & $\boldsymbol{\nu}$ \\
\hline Of consonants & レ & レ & レ & レ & $\boldsymbol{V}$ \\
\hline From talkers speaking at different rates of speed & レ & & & & \\
\hline Listening training/ repair strategies & レ & & & & \\
\hline Visual stimulus/ lip-reading option & レ & レ & レ & レ & レ \\
\hline Music & レ & & & & \\
\hline Telephone & レ & & & & \\
\hline Everyday environmental sounds & レ & レ & レ & レ & $\boldsymbol{V}$ \\
\hline Auditory memory & & $\boldsymbol{\nu}$ & $\boldsymbol{\nu}$ & $\boldsymbol{\nu}$ & $\boldsymbol{\nu}$ \\
\hline
\end{tabular}

Abbreviations: AdvBio, Advanced Bionics; CBATPs, computer- based auditory training programs; $\mathrm{Cl}$, cochlear implant.

Realizing the advances in of CBATPs that can be used at home, and the importance of auditory rehabilitation in children, this review re-emphasizes the need for future studies to establish the efficacy of the existing programs.

We have observed a lack of outcome measures in the current literature. Even though we found four other articles during the review, they could not be included because they only had one or no outcome measures. This highlights the importance of choosing an appropriate outcome measure to quantify accurately the improvements resulting from the therapy, if any. Apart from the behavioral measures, the use of electrophysiological measures has gained popularity because they aid the interpretations, when combined with behavioral and other objective tests. They are consistently used in the literature as a measure of the progress resulting from the auditory training. ${ }^{30,31}$ Hence, we suggest that the researchers who are developing new programs release them along with the documented efficacy measured using the appropriate outcome measures.

One limitation of this review regards the search performed. A few more popular databases could have been considered. Moreover, a greater number of reports could have been included if the inclusion criteria were not so strict. Discussing the existing literature, although not stringent with respect to study design, could have enabled us to address other areas that need focus while taking up further studies. Therefore, the authors expect that this review will assist in the decision-making process concerning the recommendation and purchase of CBATPs. It is our hope that this study will instigate clinical researchers to produce the outcome measures needed.

\section{Final Comments}

Computer-based auditory training programs might benefit children with HI. There are several commercially available CBATPs that indeed have plenty of concepts and activities for different age groups. However, there is a dire need for more research to establish efficacy measures for these programs. This review might provide the assistance needed by clinicians and families of children with $\mathrm{HI}$ to make program selections. In addition, this review might also provide a knowledge base on which to build further rehabilitation and outcome researches.

\section{Conflict of Interest Statement}

The authors report no conflicts of interest. The authors alone are responsible for the content and writing of the paper.

\section{References}

1 Organization WH. WHO global estimates on prevalence of hearing loss. Mortal Burd Dis Prev Blind Deaf WHO; 2012

2 Bloom S. Technologic advances raise prospects for a resurgence in use of auditory training. Hear J 2004;57(08):19-20

3 Fu QJ, Nogaki G, Galvin JJ III. Auditory training with spectrally shifted speech: implications for cochlear implant patient auditory rehabilitation. J Assoc Res Otolaryngol 2005;6(02):180-189

4 Boothroyd A. Adapting to changed hearing: the potential role of formal training. J Am Acad Audiol 2010;21(09):601-611

5 Boothroyd A. Adult aural rehabilitation: what is it and does it work? Trends Amplif 2007;11(02):63-71 
6 Fu QJ, Galvin JJ III. Perceptual learning and auditory training in cochlear implant recipients. Trends Amplif 2007;11(03): 193-205

7 Martin M. Software-based auditory training program found to reduce hearing aid return rate. Hear J 2007;60(08):32

8 Sweetow RW, Sabes JH. The need for and development of an adaptive Listening and Communication Enhancement (LACE) Program. J Am Acad Audiol 2006;17(08):538-558

9 Pallarito K. Retraining the brain when hearing aids aren't enough. Hear J 2011;64(08):25

10 Fitzpatrick EM, Brewster L. Adult cochlear implantation in Canada: results of a survey. Can J Speech Lang Pathol Audiol 2010; 34:290-296

11 Hull RH. A brief treatise on the service of aural rehabilitation. Hear J 2011;64(04):14

12 Jain A. Apps marketplaces and the telecom value chain. IEEE Wirel Commun 2011;18(04):4-5

13 Bellman S, Potter RF, Treleaven-Hassard S, Robinson JA, Varan D. The Effectiveness of Branded Mobile Phone Apps. J Interact Market 2011;25(04):191-200

14 Feijoo C, Gómez-Barroso J-L, Aguado J-M, Ramos S. Mobile gaming: Industry challenges and policy implications. Telecomm Policy 2012;36(03):212-221

15 Stacey PC, Raine CH, O'Donoghue GM, Tapper L, Twomey T, Summerfield AQ. Effectiveness of computer-based auditory training for adult users of cochlear implants. Int J Audiol 2010;49(05): 347-356

16 Sweetow R, Palmer CV. Efficacy of individual auditory training in adults: a systematic review of the evidence. J Am Acad Audiol 2005;16(07):494-504

17 Brouns K, Refaie AE, Pryce H. Auditory training and adult rehabilitation: a critical review of the evidence. Glob J Health Sci 2011; 3(01):49-63

18 Pizarek R, Shafiro V, McCarthy P, et al. Effect of Computerized Auditory Training on Speech Perception of Adults With Hearing Impairment. Perspect Aural Rehabil Its Instrum 2013;20(03):91

19 Henshaw H, Ferguson MA. Efficacy of individual computer-based auditory training for people with hearing loss: a systematic review of the evidence. PLoS One 2013;8(05):e62836
20 Moher D, Liberati A, Tetzlaff J, Altman DG; PRISMA Group. Preferred reporting items for systematic reviews and metaanalyses: the PRISMA statement. Ann Intern Med 2009; 151(04):264-269, W64

21 Glyde H, Cameron S, Dillon H, Hickson L. Remediation of spatial processing deficits in hearing-impaired children and adults. J Am Acad Audiol 2014;25(06):549-561

22 Cameron S, Dillon H. Development and evaluation of the LiSN \& learn auditory training software for deficit-specific remediation of binaural processing deficits in children: preliminary findings. J Am Acad Audiol 2011;22(10):678-696

23 Cameron S, Glyde H, Dillon H. Efficacy of the LiSN \& Learn auditory training software: randomized blinded controlled study. Audiology Res 2012;2(01):e15

24 Gatehouse S, Noble W. The Speech, Spatial and Qualities of Hearing Scale (SSQ). Int J Audiol 2004;43(02):85-99

25 Anderson KL, Smaldino JJ. The Listening Inventory For Education: an efficacy tool. Hear J 1998;16(07):494-504

26 Bench J, Kowal A, Bamford J. The BKB (Bamford-Kowal-Bench) sentence lists for partially-hearing children. Br J Audiol 1979; 13(03):108-112

27 Hornickel J, Chandrasekaran B, Zecker S, Kraus N. Auditory brainstem measures predict reading and speech-in-noise perception in school-aged children. Behav Brain Res 2011;216(02): 597-605

28 Zhang M, Miller A, Campbell MM. Overview of nine computerized, home-based auditory-training programs for adult cochlear implant recipients. J Am Acad Audiol 2014;25(04):405-413

29 Yoshinaga-Itano C, Sedey AL, Coulter DK, Mehl AL. Language of early- and later-identified children with hearing loss. Pediatrics 1998;102(05):1161-1171

30 Tremblay K, Kraus N, McGee T. The time course of auditory perceptual learning: neurophysiological changes during speech-sound training. Neuroreport 1998;9(16):3557-3560

31 Stevens C, Fanning J, Coch D, Sanders L, Neville H. Neural mechanisms of selective auditory attention are enhanced by computerized training: electrophysiological evidence from language-impaired and typically developing children. Brain Res 2008;1205:55-69 